\title{
Mechanical characteristics research of new asphalt pavement structure based on geogrid
}

\author{
Guangcong $\mathrm{Ni}^{1}$, Xiaomeng Zhang ${ }^{2}$, Xizhong $\mathrm{Xu}^{2}$, and E. Uglova ${ }^{1 *}$ \\ ${ }^{1}$ Don State Technical University, 344022, Rostov-on-Don, Russia \\ ${ }^{2}$ Shandong Transportation Research Institute, 250102, Jinan, Shandong
}

\begin{abstract}
In order to study the mechanical characteristics of new asphalt pavement structural materials, UTM testing machine and Overlay Test (OT) testing machine, four-point fatigue test, tensile test and bending strength test have been carried out on different types of grid asphalt mixtures. The result shows: the addition of different types of grids can effectively improve the mechanical properties of the asphalt concrete pavement structure; geogrid addition can improve the stress on the road surface, improve the strength of pavement materials, it can effectively alleviate early generation of fatigue cracks on the road surface; it can also effectively avoid the problem of rutting damage on the whole road surface after partial damage to the road surface; can effectively promote pavement stress dispersion, improve pavement structure stability, make the pavement structure more stable, improve its service life.
\end{abstract}

\section{Introduction}

Geogrid is a kind of geosynthetic material, because of its good mechanical properties, it has been widely used in actual engineering structures ${ }^{[1-4]}$. Most research scholars at home and abroad believe that ${ }^{[5-8]}$, adding geogrid to the asphalt concrete base can effectively improve the overall performance of the pavement structure. In this paper, by laying different types of geogrids on the asphalt concrete surface, test and analyze of the fatigue performance, tensile performance and bending performance of its mixture make an objective and correct analysis and evaluation of the mechanical properties of geogrid applied to the asphalt surface.

\section{Experiment Method}

In order to effectively and truly reflect the actual road performance of different types of geogrids in the asphalt concrete surface. This article is in accordance with JTG E20-2011 "Highway Engineering Asphalt and Asphalt Mixture Test Regulations" T0703-2011, T0736$2011^{[9]}$ and Bituminous Mixtures-Test methods for hot mix asphalt-Part 22: Wheel tracking (includes Amendment A1:2007) English version of DIN EN 12697-22:2007-10 ${ }^{[10]}$. Different types of grid asphalt mixtures are respectively used for rutting wheel forming and rotary compaction forming.

\footnotetext{
* Corresponding author: uglova.ev@yandex.ru
} 


\subsection{Geogrid}

For the stress compensation demand of the asphalt mixture surface layer, in this paper, four different types of geogrids, CFG50-50, EGA80-80, EGA100-100, and TGSG40-40, are selected and laid on the asphalt surface, respectively, and compared with the asphalt mixture without the grid (O) for comparative analysis. Table 1 shows the specifications and parameters of different types of geogrids.

Table. 1 Parameters of different types of geogrids

\begin{tabular}{|c|c|c|c|c|c|c|}
\hline \multirow{2}{*}{$\begin{array}{c}\text { Name and } \\
\text { specificatio } \\
n\end{array}$} & \multirow[t]{2}{*}{ Example } & \multirow[t]{2}{*}{$\begin{array}{c}\text { Size, } \\
\text { mm }\end{array}$} & \multicolumn{2}{|c|}{$\begin{array}{c}\text { Breaking } \\
\text { strength, } K N / m\end{array}$} & \multirow[t]{2}{*}{$\begin{array}{c}\text { Elongation, } \\
\%\end{array}$} & \multirow[t]{2}{*}{$\begin{array}{l}\text { Corrosion } \\
\text { resistance }\end{array}$} \\
\hline & & & Radial & Weft & & \\
\hline CFG50-50 & & $25 * 25$ & $\geq 50$ & $\geq 50$ & $\leq 2$ & Excellent \\
\hline EGA80-80 & & $20 * 20$ & $\geq 80$ & $\geq 80$ & $\leq 3$ & Excellent \\
\hline $\begin{array}{c}\text { EGA100- } \\
100\end{array}$ & & $20 * 15$ & $\geq 100$ & $\geq 100$ & $\leq 13$ & $\begin{array}{c}\text { 优良 } \\
\text { Excellent }\end{array}$ \\
\hline TGSG4040 & & $15 * 15$ & $\geq 40$ & $\geq 40$ & $\leq 15$ & Excellent \\
\hline
\end{tabular}

\subsection{Asphalt mixture}

Aiming at the characteristics of asphalt sand and AC-25 two types of asphalt mixtures, in this paper, dry, clean, and angular limestone and A-grade 70\# matrix asphalt are selected as raw materials (Table 2), the asphalt content is $6.8 \%, 3 \sim 5 \mathrm{~mm}$ limestone accounts for $35 \%$; $0 \sim 3 \mathrm{~mm}$ limestone accounts for $60 \%$, mineral powder accounts for $5 \%$ (Table 3 and Figure 1).

Table. 2. Asphalt performance index test results.

\begin{tabular}{|c|c|c|}
\hline Test index & Measured value & Skills requirement \\
\hline Penetration index PI & -0.8 & $-1.4 \sim 1.0$ \\
\hline $10^{\circ} \mathrm{C}$ ductility, $\mathrm{cm}$ & $>20$ & $\geq 20$ \\
\hline $15^{\circ} \mathrm{C}$ ductility, cm & $>100$ & $\geq 100$ \\
\hline Softening Point, ${ }^{\circ} \mathrm{C}$ & 47 & $\geq 44$ \\
\hline $60^{\circ} \mathrm{C}$ dynamic viscosity, $(\mathrm{Pa} \cdot \mathrm{s})$ & 181 & $\geq 180$ \\
\hline Distillation wax mass fraction, $\%$ & 1.9 & $\leq 2.2$ \\
\hline Solubility, \% & 99.6 & $\geq 99.5$ \\
\hline $15^{\circ} \mathrm{C}$ Density, $(\mathrm{g} \cdot \mathrm{cm}-3)$ & 1.00 & 实测记录 \\
\hline Quality change, $\%$ & 0.5 & $\leq \pm 0.8$ \\
\hline $10^{\circ} \mathrm{C}$ ductility, $\mathrm{cm}$ & 9 & $\geq 6$ \\
\hline
\end{tabular}




\begin{tabular}{|c|l|c|c|}
\hline \multirow{2}{*}{ TFOT } & $15^{\circ} \mathrm{C}$ ductility, $\mathrm{cm}$ & 16 & $\geq 15$ \\
\cline { 2 - 4 } & Residual penetration ratio, $\%$ & 63 & $\geq 61$ \\
\hline
\end{tabular}

Table. 3. Aggregate gradation.

\begin{tabular}{|c|c|c|c|c|c|c|c|c|c|}
\hline $\begin{array}{c}\text { Specification } \\
\text { name }\end{array}$ & 13.2 & 9.5 & 4.75 & 2.36 & 1.18 & 0.6 & 0.3 & 0.15 & 0.075 \\
\cline { 2 - 10 } & 100.0 & 100.0 & 78.7 & 5.6 & 1.9 & 1.5 & 1.5 & 1.5 & 1.3 \\
\hline Limestone 3-5 & 100.0 & 100.0 & 100.0 & 96.4 & 67.5 & 35.1 & 21.4 & 10.1 & 7.3 \\
\hline $\begin{array}{c}\text { Machine-made } \\
\text { sand 0-3 }\end{array}$ & 100.0 & 100.0 & 100.0 & 100.0 & 100.0 & 100.0 & 100.0 & 96.1 & 83.3 \\
\hline Mineral powder & 100.0 & 100.0 & 92.5 & 64.8 & 46.2 & 26.6 & 18.4 & 11.4 & 9.0 \\
\hline $\begin{array}{c}\text { Determine the } \\
\text { ratio }\end{array}$ & & & & & & & & & \\
\hline
\end{tabular}



Fig.1. Aggregate grading curve

As can be seen from the above chart, the performance indicators of the raw materials selected in this paper meet the requirements of relevant technical specifications.

\subsection{Four-point fatigue test}

In order to determine the fatigue resistance of four different types of grid asphalt mixtures at specified temperatures and loading rates [11-13]. According to JTG E20-2011 "Highway Engineering Asphalt and Asphalt Mixture Test Regulations" T0703-2011 Asphalt Mixture Wheel Rolling Method ${ }^{[9]}$. Using 500mm*180mm*100mm trial mold (Figure 2), First, lay a layer of asphalt sand structure within $50 \mathrm{~mm}$ of the bottom of the trial layer. after leveling and tamping, immediately place the grille when the temperature of the asphalt sand is high, fill the trial mold with the remaining tar sand, and roll it again to compact it, Finally, a doublelayer tar sand + grid composite structure layer is made (Figure 3). Note: The force direction of geogrid reinforcement belt is the same as the direction of rolling. 


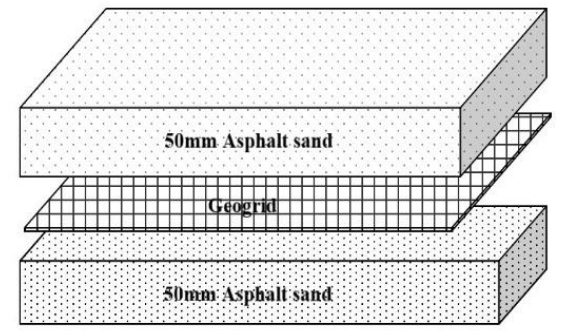

Fig. 2. $500 \mathrm{~mm} * 180 \mathrm{~mm} * 100 \mathrm{~mm}$ Schematic diagram of specimen

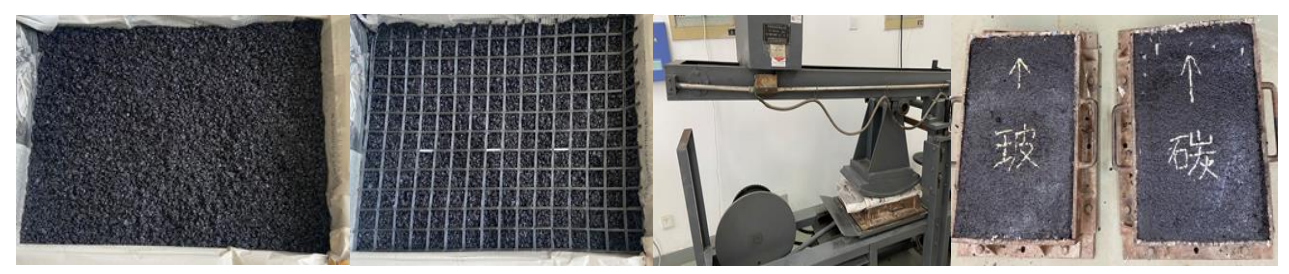

Fig. 3. Schematic diagram of the test piece forming process

After the specimens have been kept in good health, cut into prism beams of $380 \mathrm{~mm} * 63.5 \mathrm{~mm} * 50 \mathrm{~mm}$ (Figure 4). UTM-100 testing machine equipped with load sensor, displacement meter and data acquisition system is used for test analysis.

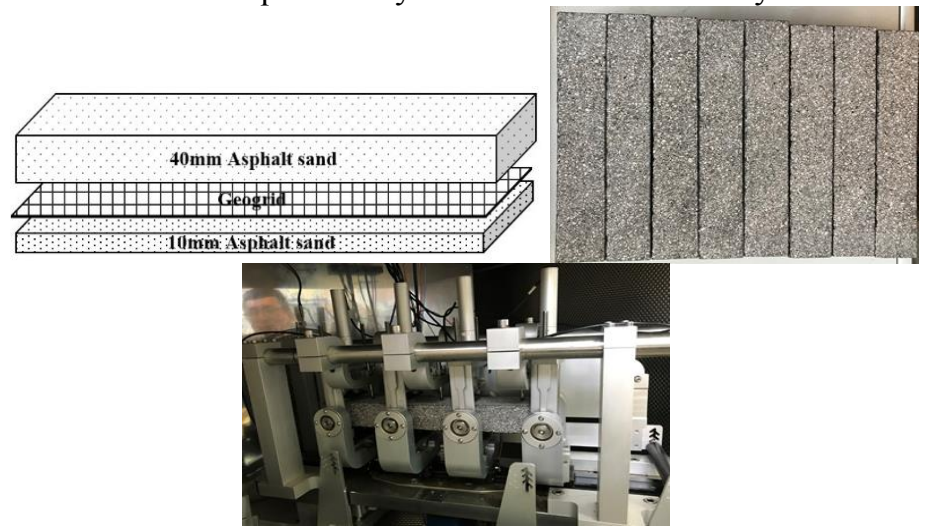

Fig. 4. Four-point fatigue test specimen

\subsection{Overlay Test}

Overlay Test (OT) test is a simple, fast and effective experimental method to test the anticracking performance of asphalt mixture ${ }^{[14]}$. In order to verify the crack resistance of different types of grid asphalt mixtures ${ }^{[15-16]}$, this experiment is in accordance with JTG E202011 "Highway Engineering Asphalt and Asphalt Mixture Test Regulations" T0736-2011 Asphalt Mixture SCG Rotary Compaction Specimen Manufacturing Method ${ }^{[9]}$. Use a test mold of $160 \mathrm{~mm} * 150 \mathrm{~mm}$ (Figure 5), load $2625 \mathrm{~g}$ of material in the test mold, perform rotation compaction 50 times, then put it into the grid, add the remaining material, and then rotate and compact 100 times (Figure 6). Note: The force direction of geogrid reinforcement is consistent with the direction of rotation. 


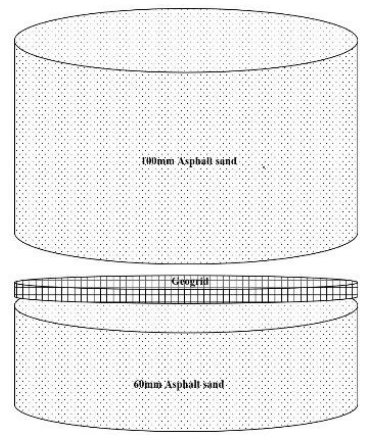

Fig.5. $150 \mathrm{~mm} * 160 \mathrm{~mm}$ Schematic diagram of test piece

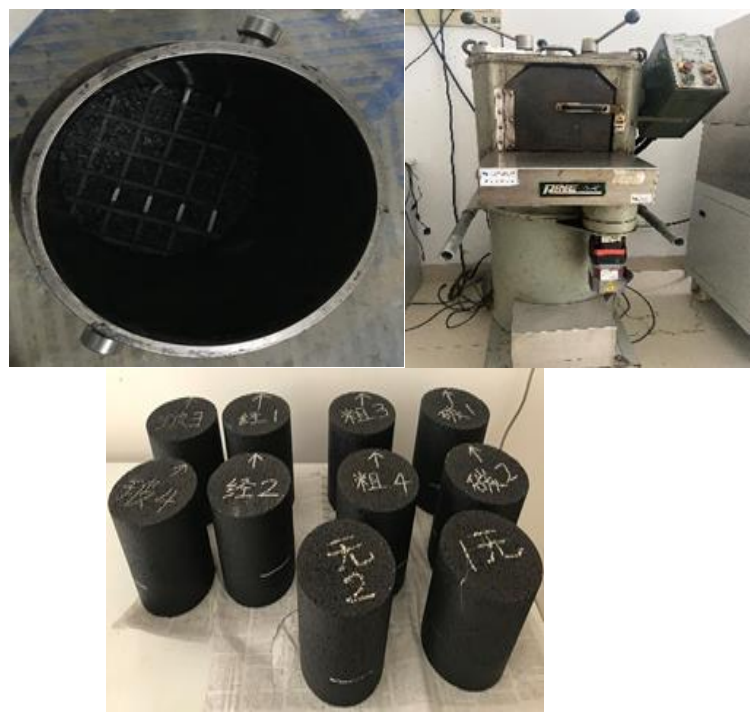

Fig. 6. Schematic diagram of the test piece forming process

After the curing is completed, cut into $150 \mathrm{~mm} * 75 \mathrm{~mm} * 38 \mathrm{~mm}$ test pieces respectively (Figure 7). Using the OT testing machine, tensile cracking test of asphalt mixture was carried out under the condition of $25^{\circ} \mathrm{C}, 10 \mathrm{~s}, 0.635 \mathrm{~mm}$ cyclic displacement.

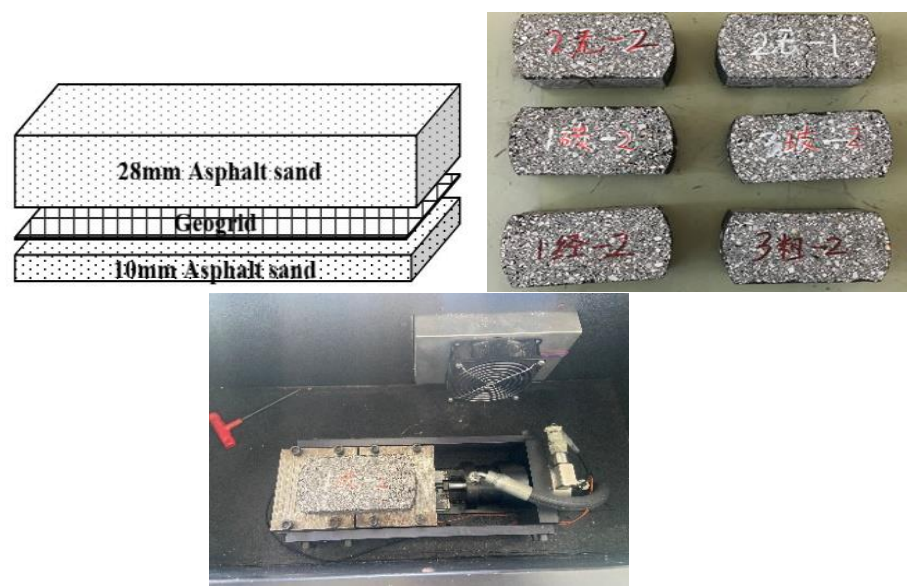

Fig. 7. OT test specimen after rotary compaction 


\subsection{Flexural strength test}

In order to determine the bending strength of four different types of grid asphalt mixture ${ }^{[17-}$ ${ }^{18]}$. According to JTG E20-2011 "Highway Engineering Asphalt and Asphalt Mixture Test Regulations" T0703-2011 Asphalt Mixture Wheel Rolling Method [9]. Using $300 \mathrm{~mm} * 300 \mathrm{~mm} * 100 \mathrm{~mm}$ trial mold (Figure 8), First, pave the bottom of the trial mold with $20 \mathrm{~mm}$ asphalt sand, after leveling and tamping, add grille and spread hot asphalt, then pave $80 \mathrm{~mm}$ AC-25 asphalt mixture (Figure 9). Note: The force direction of geogrid reinforcement belt is the same as the direction of rolling.

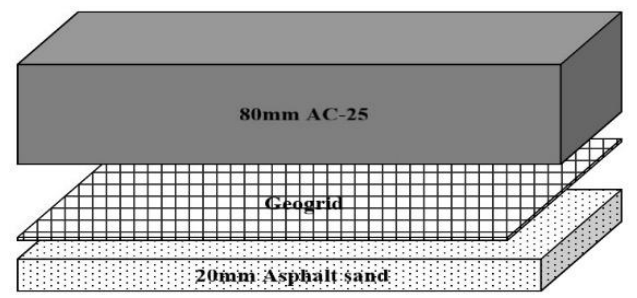

Fig. $8300 \mathrm{~mm} * 300 \mathrm{~mm} * 100 \mathrm{~mm}$ Schematic diagram of specimen

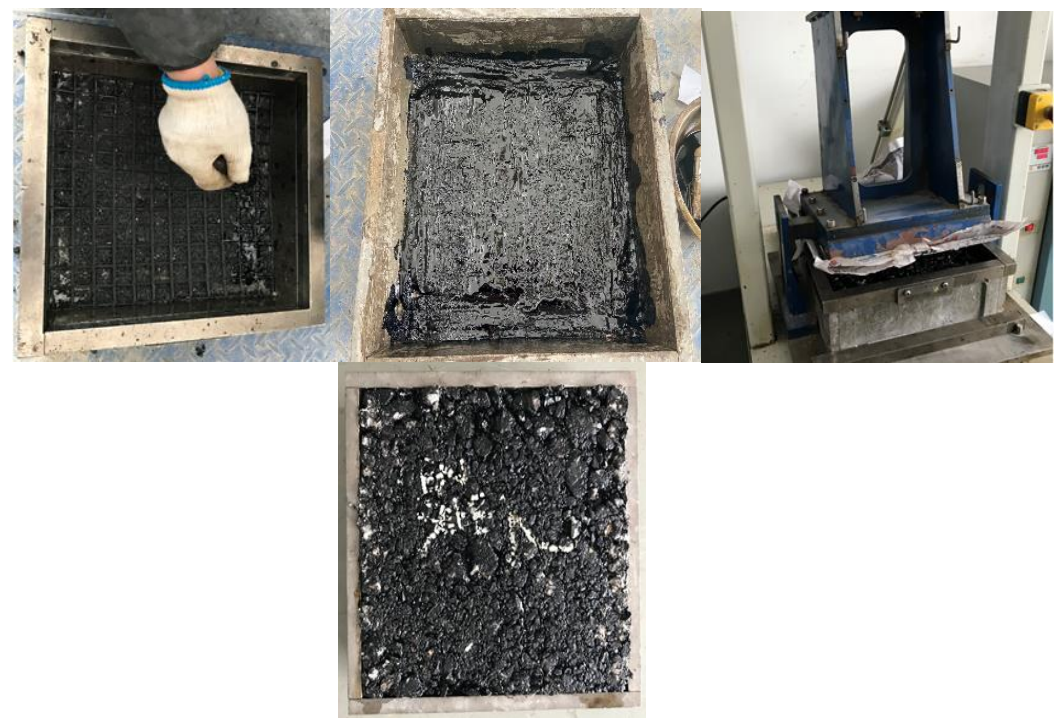

Fig. 9. Schematic diagram of the test piece forming process

After the specimen is kept in good health for 48 hours, cut into $250 \mathrm{~mm} * 50 \mathrm{~mm} * 50 \mathrm{~mm}$ prism trabeculae respectively. UTM-100 testing machine was used to carry out the bending test of asphalt mixture under the conditions of $15^{\circ} \mathrm{C}, 10 \mathrm{~Hz}$ and $10 \mu \mathrm{E}$ (Figure 10).
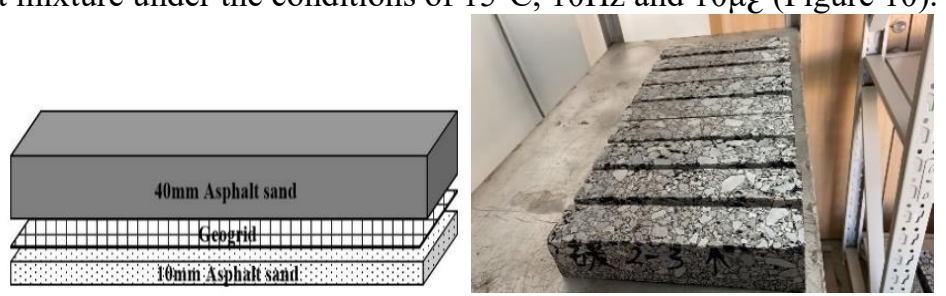


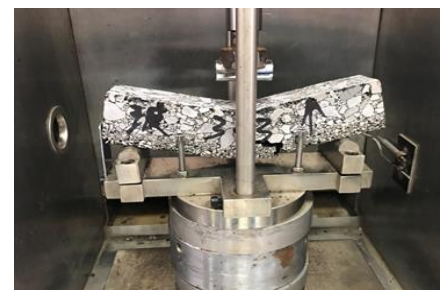

Fig. 10 Bend test

\section{Analysis of test results}

\subsection{Fatigue performance analysis}

UTM-100 testing machine equipped with load sensor, displacement meter and data acquisition system, the test analysis is carried out at $15^{\circ} \mathrm{C}, 10 \mathrm{~Hz}, 400 \mu \mathrm{E}$ continuous bias sine wave loading mode. The relationship between the loading times and modulus of 4 different types of grid asphalt mixtures is obtained (Figure 11).

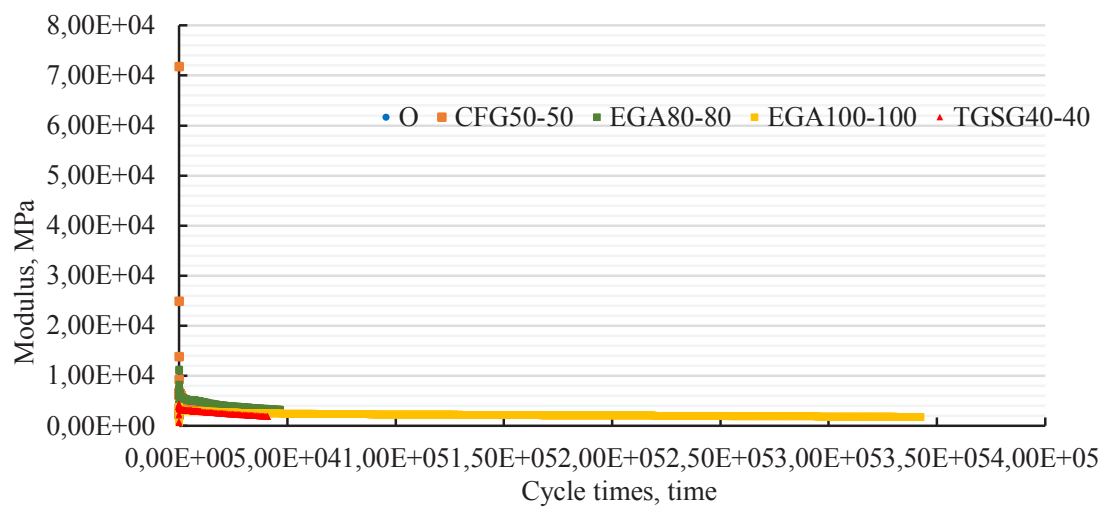

Fig. 11. Four-point fatigue test results

According to JTG E20-2011 "Highway Engineering Asphalt and Asphalt Mixture Test Regulations" T0739-2011 Test Specification ${ }^{[9]}$. Using the relationship between the number of cycles and the modulus when the specimen is broken, in turn, the maximum tensile and compressive strain value and stiffness modulus of the mixture can be obtained. The calculation formula is:

$$
\begin{gathered}
\sigma_{t}=\frac{L \times P}{w \times h^{2}} \\
\varepsilon_{t}=\frac{12 \times \delta \times h}{3 \times L^{2}-4 \times a^{2}} \\
S=\frac{\sigma_{t}}{\varepsilon_{t}}
\end{gathered}
$$

Where $\sigma_{t}$ is maximum tensile stress $(\mathrm{Pa}) ; \varepsilon_{t}$ is maximum tensile strain $(\mathrm{m} / \mathrm{m}) ; S$ is bending stiffness $(\mathrm{Pa}) ; P$ is peak load $(\mathrm{N}) ; L$ is beam span, that is, the distance between two pieces of furniture at the outer end $(0.357 \mathrm{~m}),(\mathrm{m}) ; w$ is width $(\mathrm{m}) ; h$ is high $(\mathrm{m}) ; \delta$ is maximum strain at beam center $(\mathrm{m}) ; a$ is center distance between adjacent chucks $(\mathrm{L} / 3,0.119 \mathrm{~m}),(\mathrm{m})$;

The fatigue test results of different types of grid asphalt mixtures can be calculated by Eq (1), (2), (3). 
Table. 4. Fatigue test results of different types of grid asphalt mixture.

\begin{tabular}{|c|c|c|c|c|c|c|c|c|}
\hline $\begin{array}{c}\text { Specification } \\
\text { type }\end{array}$ & $\begin{array}{c}\text { Cycle } \\
\text { time/time }\end{array}$ & $\begin{array}{c}\text { greatest } \\
\text { pressure, } \\
\mathrm{KPa}\end{array}$ & $\begin{array}{c}\text { Maximum } \\
\text { load/KN }\end{array}$ & $\sigma / \mathrm{KPa}$ & $\mu \varepsilon / \mathrm{mm}$ & $\mathrm{S} / \mathrm{MPa}$ & $\mathrm{E}, \mathrm{MJ} / \mathrm{m}^{3}$ & $\begin{array}{l}\text { Lift } \\
\text { rate, } \\
\%\end{array}$ \\
\hline CFG50-50 & 25626 & 3538.32 & 1.383 & 155.45 & 0.068 & 10700.67 & 1858.34 & -21.0 \\
\hline EGA80-80 & 46702 & 3653.07 & 1.389 & 156.16 & 0.070 & 10821.39 & 4070.50 & 44.1 \\
\hline EGA100-100 & 342358 & 1989.14 & 0.982 & 110.38 & 0.069 & 7616.32 & 83153.78 & 955.6 \\
\hline TGSG40-40 & 40779 & 2335.13 & 0.934 & 105.08 & 0.064 & 6720.60 & 2106.42 & 26.0 \\
\hline O & 32422 & 2638.26 & 1.013 & 113.86 & 0.066 & 7515.85 & 2114.31 & - \\
\hline
\end{tabular}

Analyzing the test results in Figure 11 and Table 4, we can find that: The fatigue resistance of the four types of asphalt mixtures from strong to weak are: EGA100-100>EGA8080>TGSG40-40>CFG50-50; The fatigue life of EGA100-100 asphalt mixture has increased by an order of magnitude compared with the other three types, its anti-fatigue performance is the best; Compared with O, the fatigue life of EGA100-100 is increased by $955 \%$, and the effect is remarkable; The fatigue life of EGA80-80 and TGSG40-40 are increased by $44.1 \%$ and $26 \%$ respectively, it shows that it can effectively increase the service life of asphalt mixture to a certain extent, both provide positive help to improve the fatigue resistance of asphalt mixtures; Compared with O, CFG50-50 asphalt mixture does not improve the fatigue life of asphalt mixture, but reduces it by $21 \%$, can not achieve the effect of improving the use time of the road.

Through data analysis: Three types of grids: EGA80-80, EGA100-100, and TGSG40-40, can improve the fatigue resistance of asphalt mixtures. improve the service life of asphalt mixture pavement,

\subsection{Anti-cracking performance analysis}

According to Bituminous mixtures-Test methods for hot mix asphalt-Part 22: Wheel tracking (includes Amendment A1:2007) English version of DIN EN 12697-22:2007-10 standard operation method ${ }^{[10]}$. The OT test was carried out on different types of grid asphalt mixture specimens at $20^{\circ} \mathrm{C}$ under the condition of cyclic loading 1000 times or the loading force attenuated to the initial force ${ }^{[9]}$. The test results are shown in Table 5.

Table. 5. OT test results.

\begin{tabular}{|c|c|c|c|c|c|}
\hline $\begin{array}{c}\text { Specification } \\
\text { type }\end{array}$ & $\begin{array}{c}\text { Cycle } \\
\text { times/time }\end{array}$ & $\begin{array}{c}\text { Initial load } \\
/ \mathrm{KN}\end{array}$ & $\begin{array}{c}\text { End load } \\
/ \mathrm{KN}\end{array}$ & $\begin{array}{c}\text { Maximum load } \\
/ \mathrm{KN}\end{array}$ & $\begin{array}{c}\text { Attenuation } \\
\text { rate } \\
/ \%\end{array}$ \\
\hline CFG50-50 & 1000 & 1.83 & 0.53 & 2.63 & 71.23 \\
\hline EGA80-80 & 1000 & 1.57 & 0.66 & 2.05 & 58.61 \\
\hline EGA100-100 & 1000 & 1.70 & 0.52 & 2.40 & 69.72 \\
\hline TGSG40-40 & 1000 & 1.68 & 0.71 & 2.59 & 58.19 \\
\hline O & 247 & 1.76 & 0.73 & 2.78 & 59.27 \\
\hline
\end{tabular}

According to the test results in Table 5, the O-type asphalt mixture broke after being loaded to 247 stretching cycles; The other 4 types of grid asphalt mixture specimens have withstood 1000 tensile cycles. but the attenuation rate of each type of mixture is different; TGSG 40-40 type after 1000 cycles, the load is attenuated by $58.19 \%$, the attenuation rate is the smallest; The initial load of EGA80-80 type specimen is the smallest, which is $1.57 \mathrm{kN}$; CFG50-50 attenuates $71.23 \%$ after 1000 cycles, and its attenuation rate is the largest, but the highest initial load is the largest, $1.83 \mathrm{kN}$. It can be found through experimental data, EGA8080 and TGSG40-40 two types of mixture specimens have the best crack resistance, in actual engineering applications, it can effectively alleviate the fatigue crack damage of the asphalt pavement. 
In order to further verify the crack resistance of different types of grid mixtures, take the upper and lower layers of the same rotating compaction specimen for OT test, the result is shown in Figure 12.
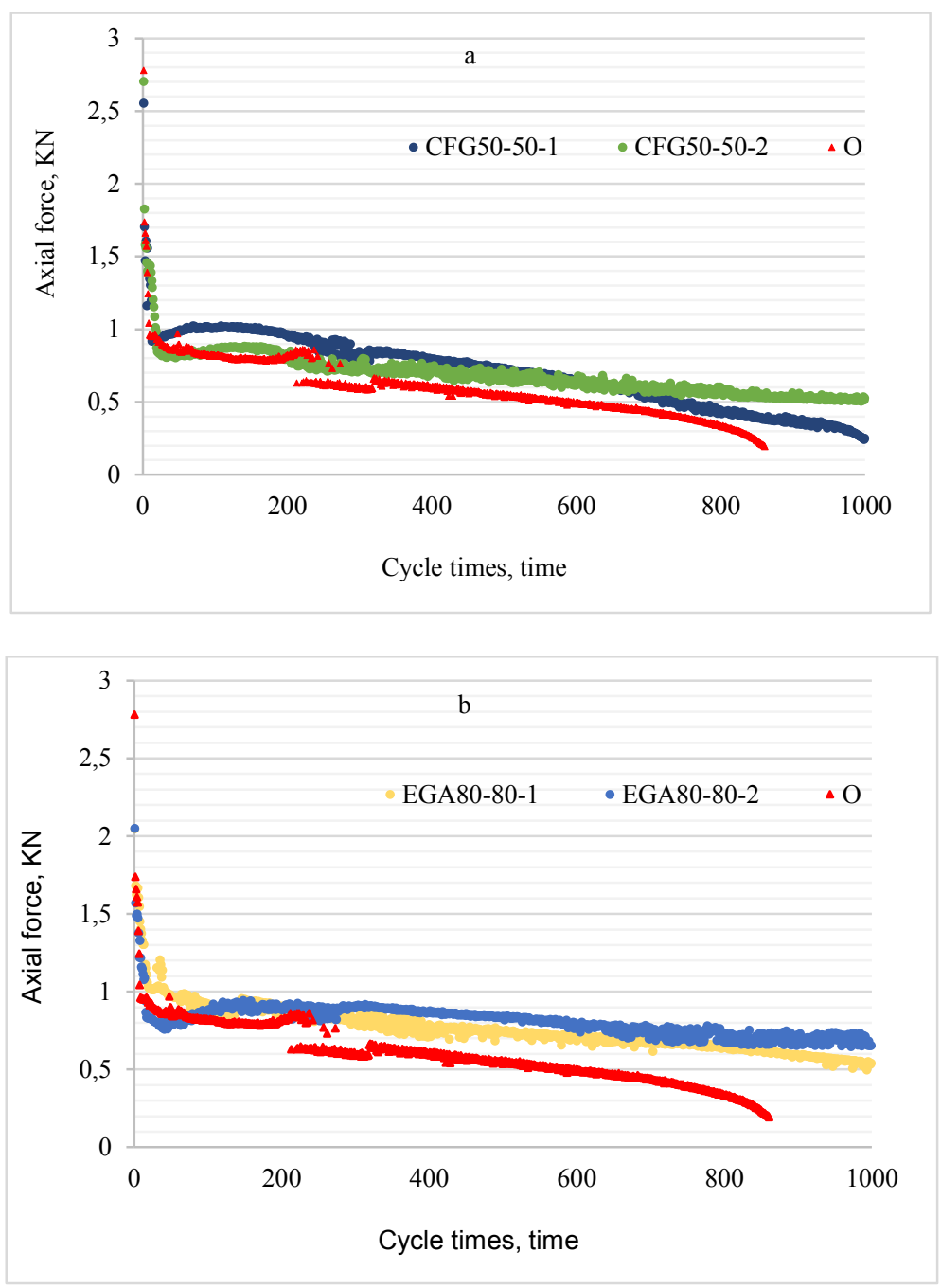



Note: The same test piece -1 is without grille, -2 is with grille, and " $\mathrm{O}$ " is the sample without grille for 150 times of single rotation compaction.

Fig. 12. OT test results of different types of grid mixtures under the same test piece

Through the test results, it can be found that, although the compaction times of the upper and lower specimens of the same rotating compaction specimen are different, but CFG50-50, EGA80-80, EGA100-100, TGSG40-40 four types of specimens can withstand 1000 cycles of stretching, the stretching effect is better than "O" type. This shows that the number of compactions does not mean that the number of stretches that can withstand is large; The starting force $\mathrm{O}$ type mixtures are all greater than the four different types of mixtures, it shows that the addition of the grid makes the asphalt mixture improve its tensile resistance to varying degrees.

Compared with Figure 12(a) and (b), it is found that: when the test is over, the force of CFG50-50-2 $(0.51 \mathrm{kN})$ is obviously greater than that of CFG50-50-1 $(0.24 \mathrm{kN})$, it shows that 
the grid can effectively resist the tensile deformation time of the asphalt mixture, improve the crack resistance of asphalt mixture; The results of Figure 12 (c) and (d) show that the effect is not obvious. The above experiment description, in actual engineering applications, the addition of the grid can effectively improve the crack resistance of the asphalt mixture, relieve the generation of early fatigue cracks on the road surface.

\subsection{Bending performance analysis}

In order to further verify the bending failure characteristics of different types of grid asphalt mixtures at the specified temperature and loading rate ${ }^{[19]}$. This experiment uses UTM-100 testing machine, the bending strength test results of four different types of grid mixtures were obtained under the conditions of $15^{\circ} \mathrm{C}, 50 \mathrm{~mm} / \mathrm{min}$, and $400 \mu \varepsilon$ (Figure 13).

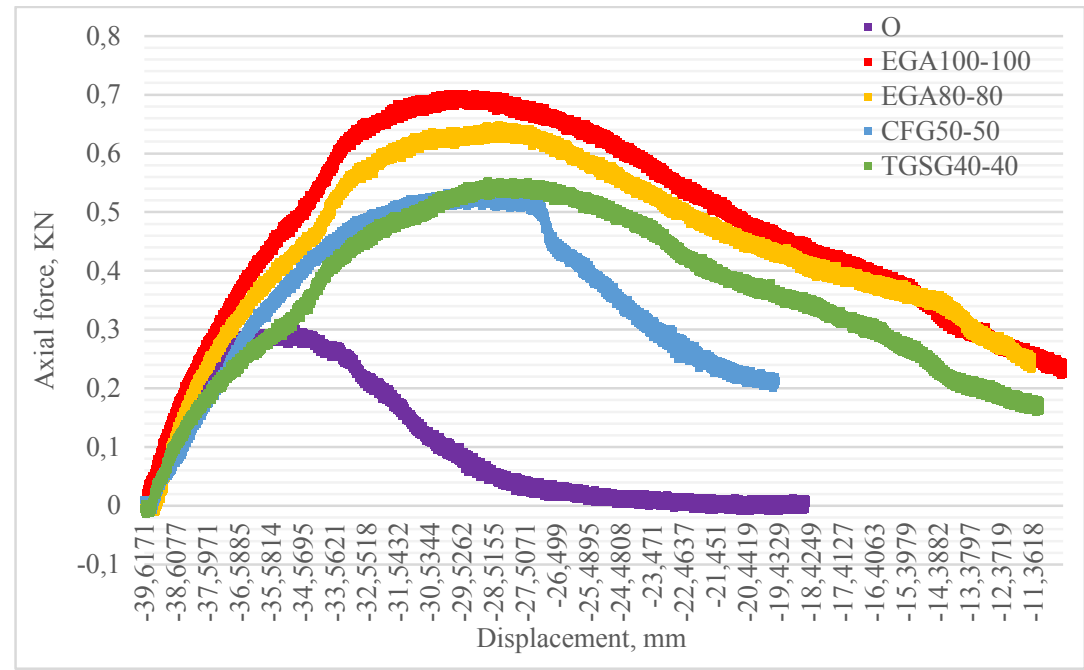

Fig. 13. Flexural strength test results of different types of grid asphalt mixtures at $15^{\circ} \mathrm{C}$

According to the test results in Figure 13, the bending strength of the grid mixture specimens has been significantly improved; The maximum bending tensile strength of the four different types of grid mixtures is in order: EGA100-100>EGA80-80>TGSG40$40>$ CFG50-50; Compared with the "O" shaped bending strength, the bending strength is greatly improved, it shows that the addition of the grille has a certain effect on the bending strength of the asphalt mixture; At the same time, the deformation and failure curves of the four different types of grid specimens are also greatly changed from those of the "O" type, the curve of the specimen after failure is more relaxed, the destruction process is slower, it shows that the addition of the grille can effectively reduce the rapid deformation and damage of the road surface.

According to JTG E20-2011 "Highway Engineering Asphalt and Asphalt Mixture Test Regulations" T0715-2011 Test Specification ${ }^{[9]}$, using the failure load and mid-span deflection when the specimen fails, obtain the maximum flexural tensile strain value of the asphalt mixture. The calculation formula is:

$$
\begin{gathered}
R_{B}=3 L P_{B} / 2 b h^{2} \\
\varepsilon_{B}=6 h d / L^{2}
\end{gathered}
$$




$$
S_{B}=R_{B} / \varepsilon_{B}
$$

Where $R_{B}$ is bending and tensile strength when the specimen is broken, (MPa); $\varepsilon_{B}$ is maximum bending and tensile strain when the specimen fails, $(\mu \varepsilon) ; S_{B}$ is bending stiffness modulus when the specimen fails, $(\mathrm{MPa}) ; P_{B}$ is maximum load when the specimen fails, $(\mathrm{N})$; $L$ is the span of the specimen, $(\mathrm{mm}) ; b$ is the width of the cross-terminal interview, $(\mathrm{mm}) ; h$ is the height of the cross-terminal interview, $(\mathrm{mm}) ; d$ is mid-span deflection when the specimen fails, (mm)

According to Eq (4), (5), (6), the maximum flexural tensile strength and maximum flexural tensile strain values of different types of grid asphalt mixtures can be obtained (Table $6)$.

Table. 6. Results of bending failure test.

\begin{tabular}{|c|c|c|c|}
\hline $\begin{array}{c}\text { Specification } \\
\text { type }\end{array}$ & $\begin{array}{c}\text { Maximum bending } \\
\text { strength /MPa }\end{array}$ & $\begin{array}{c}\text { Maximum bending } \\
\text { strain /MPa }\end{array}$ & $\begin{array}{c}\text { Bending stiffness } \\
\text { modulus /MPa }\end{array}$ \\
\hline O & 0.84 & 0.034 & 24.90 \\
\hline EGA100-100 & 1.69 & 0.075 & 22.44 \\
\hline EGA80-80 & 1.56 & 0.082 & 19.10 \\
\hline TGSG40-40 & 1.33 & 0.080 & 16.56 \\
\hline CFG50-50 & 1.28 & 0.070 & 18.31 \\
\hline
\end{tabular}

According to the test results in Table 6, the maximum flexural tensile strength and strain values of the four different types of grid asphalt mixtures are greater than those of the "O" type grid asphalt mixture, and the stiffness modulus values are the opposite; The maximum flexural tensile strength and strain of the EGA100-100 type is the largest, is twice as much as "O" type, the bending stiffness modulus is not much different, it shows that the bending and tensile strength effect of this type of grille is the most obvious;

Compared with O-type asphalt mixture, CFG50-50 type asphalt mixture has the smallest bending stiffness modulus, the maximum bending tensile strength and maximum bending tensile strain of the CFG50-50 type are both the smallest. but better than "O" type asphalt mixture; Through analysis, the asphalt mixture added to geogrid can increase the bending strength of the asphalt mixture, effectively improve the rutting problem caused by fatigue on the asphalt concrete pavement.

\section{Conclusions}

(1) Geogrid asphalt mixture can not only improve the strength of pavement materials, improve the stress on the road surface, it can also improve its bending strength, delay the development of fatigue cracks on the road surface. Effectively avoid rutting caused by reducing the stability of the pavement structure after partial damage.

(2) The addition of geogrid can effectively limit the displacement and deformation of particles in the asphalt concrete, improve the tensile strength of the material, this reduces the possibility of cracks due to stress concentration.

(3) The geogrid asphalt mixture can not only promote the stress dispersion of the road surface, but can also improve the overall modulus of the pavement structure, to improve the structure stability, make the asphalt concrete pavement structure more stable, improve its service life.

\section{References}

1. Guo Ming, Sichuan Building Materials 46 (12), 86-87 (2020). 
2. Yang Guangqin, The theory and engineering application of geogrid-reinforced soil structure[M] (Beijing: Science Press, 2010)

3. Wang Rideng, Ying Gongbang, Li Xianghang, China Science Paper 15 (12), 1371-1376 (2002).

4. Li Xiaoshuo, Huang Jingyun, Traffic construction and management. 05, 92-93 (2020).

5. Xu Chao, Liao Xingyue, Rock and soil mechanics 32(2), 43-48 (2011).

6. T. Tanchaisawat, D.T. Bergado, P. Voottipruex, et al., Geotextiles and Geo me mbranes 28(1), 119-127 (2010).

7. M.R. Abdi, M.A. Arjo mand, Geotextiles and Geo me mbranes. 29(6), 588-595 (2010).

8. Ana Cristina C.F. Sieira, Denise M.S. Gerscovich, Alberto S.F.J. Sayao, Geotextiles Geo me mbranes 27 (4), 241-253 (2009).

9. Ministry of Transport of the People's Republic of China. JTG E20-2011 «Test Regulations of Asphalt and Asphalt Mixture for Highway Engineering» [S].

10. Bituminous mixtures-Test methods for hot mix asphalt-Part 22: Wheel tracking (includes Amendment A1:2007) English version of DIN EN 12697-22:2007-10

11. Liu Jianlan, Wang Chaohui, Wang Xuancang. Journal of Traffic and Transportation Engineering 9 (2), 22-27 (2009).

12. Kong Linyun, Zhou Jinchuan, Li Hongyan, Petroleum Pitch 18 (3), 6-9 (2004).

13. Wang Shuyun, Zhang Jinxi, Miao Yinghao, et al., Journal of Beijing University of Technology 35 (9), 1209-1214 (2009).

14. Yan Kezhen, Wang Shaoquan, Tian Shan, et al., Journal of Hunan University (Natural Sciences) 47 (1),108-115 (2020).

15. Li Xinghai, Zhou Xuli, Zhang Tao, et al., Journal of China \&Foreign Highway 35 (3), 303-305 (2015).

16. Zhai Ruixin, Chen Yongman, Yu Qinghua, et al., Journal of Functional Materials 48 (9), 9129-9135 (2017).

17. Mo Shixiu, Kong Lingyun, Highway Traffic Technology 32 (4), 39-42 (2006).

18. Xu Zhongjun, Zhang Xiaoning, Wang Jiani, et al., Highway Traffic Technology 25 (1), 33-37 2008

19. Tan Ling, Xiang Yungui, Highway 61 (11), 53-57 (2016). 